\title{
RECICLAGEM DE RESÍDUOS DE CONSTRUÇÃO E DEMOLIÇÃO (RCD): UM ESTUDO DE CASO NA USINA DE BENEFICIAMENTO DE RESÍDUOS DE PETROLINA-PE
}

\author{
Carolina Larissa Vasconcelos e Freita \\ Universidade Federal do Vale do São Francisco - UNIVASF \\ Vivianni Marques Leite dos Santos \\ Doutora em Química \\ Universidade Federal do Vale do São Francisco - UNIVASF \\ vivianni.santos@univasf.edu.br \\ José Edilson dos Santos Júnior \\ Especialista em Saneamento e Gestão Ambiental \\ Universidade Federal do Vale do São Francisco - UNIVASF \\ jose.edilson@univasf.edu.br \\ Thaiane Carla Carvalho da Silva \\ Bióloga \\ Central de Tratamento de Resíduos de Petrolina \\ thaiane@ctrpetrolina.com.br
}

Graduada em Engenharia de Produção pela Universidade Federal do Vale do São Francisco - UNIVASF

\section{RESUMO}

O desenvolvimento da construção civil no Brasil tem aumentado expressivamente a quantidade de Resíduos de Construção e Demolição (RCDs). A partir da Resolução No. 307/2002 do Conama e da Política Nacional de Resíduos Sólidos, o poder público municipal passou a ser responsável por estabelecer ações para o gerenciamento dos RCDs ou "entulhos" de obra e as empresas de construção civil para destinação final correta daqueles resíduos, visando diminuir os impactos ambientais, sociais e financeiros causados pela sua deposição irregular. Diante deste cenário, a prefeitura de Petrolina/PE, em parceria com a CTRP, implantou, em 2008, uma Usina de Beneficiamento de Entulho (UBE). Com o intuito de identificar as potencialidades e fragilidades do processo de reciclagem de RCDs e propor melhorias para seu gerenciamento, foi realizado um estudo de caso, com acompanhamento do processo, pesquisa documental e entrevistas semiestruturadas com responsáveis pela UBE. As principais fragilidades estão na falta de segregação na fonte, na ineficiência da coleta e transporte dos resíduos, na presença de contaminantes, nos impactos ambientais da operação de reciclagem e na baixa resistência dos blocos produzidos. Como potencialidade, destaca-se a capacidade de processamento da UBE, a qual pode processar até 2600 toneladas de RCD por mês. Entre as proposições de melhorias, sugere-se o desenvolvimento de programas para segregação na fonte e para coleta de RCDs, além de parceria com a Universidade para melhoria da qualidade do produto.

Palavras-chave: Beneficiamento de entulhos; Construção civil; Impacto ambiental.

\section{RECYCLING OF CONSTRUCTION AND DEMOLITION WASTE (CDW): A CASE STUDY IN WASTE PROCESSING PLANT IN PETROLINA-PE}

\section{ABSTRACT}

The development of the construction industry in Brazil has increased significantly the quantity of construction and demolition wastes (CDW's). From the Resolution n. 307/2002 from Conama and National Politic Waste Solid, the municipal governments became responsible for establishing actions for the correct management of construction and demolition waste (CDW's) or 'spoils' of work, and companies in the sector for the correct disposal of wastes in order to reduce the environmental, social and financial impacts caused by irregular disposal wastes. Based on this current scenario, the city council of Petrolina/PE and its partner CTRP, implemented, in 2008, a waste processing plant (WPP). Aiming to identify strengths and weaknesses in the recycling process of the CDW's and also suggest improvements to its management we conducted a case study, including the monitoring of the process. Also documental review and semi-structured interviews were conducted with senior employees of the WPP. The main weaknesses found are the lack of segregation at source, inefficiency in the collection and transportation of waste, presence of contaminants, environmental impacts of recycling operation and low resistance of the waste blocks produced. A strength point is in the UBE processing capacity, which has production capacity of 2600 tons of CDW per month. Among the propositions of improvements, the results suggested the development programs for segregation at source and collection CDW's, as well as partnership with the University to improve the quality of the product.

Key words: Civil construction; Environmental impact; Waste processing. 


\section{INTRODUÇÃO}

A conservação do meio ambiente tem sido uma preocupação mundial, uma vez que os recursos naturais não são infinitos e a natureza não é capaz de absorver a produção exagerada de resíduos. Tal geração de resíduos é reflexo do crescimento populacional, mudança de hábitos e intensificação do consumo (Prado Filho \& Sobreira, 2007).

O setor da construção civil, apesar de ser destaque na economia de um país, possui agravantes, em razão das alterações provocadas no meio ambiente. Nesse setor, são constatados problemas ambientais desde a extração da matéria-prima em jazidas, até a destinação final dos resíduos (Farias et al., 2011).

De acordo com Santos (2008), é significativa a geração de resíduos sólidos urbanos no município de Petrolina/PE, acarretando danos sociais, econômicos e ambientais para a população. Naquele estudo, o autor observou que era comum a deposição irregular de Resíduos de Construção e Demolição (RCDs) em vários pontos da cidade. No período de outubro a novembro de 2007, em torno de 714 toneladas de RCDs foram depositados, inadequadamente, em 11 pontos da área urbana (áreas de despejos não-oficiais ou bota-fora).

Diante desse cenário e da necessidade de atendimento da Resolução $n^{\circ}$ 307/2002 do Conselho Nacional do Meio Ambiente (Conama, 2002) e da Lei $\mathrm{n}^{\circ}$ 12.305, de 2 de agosto de 2010 (Política Nacional de Resíduos Sólidos - PNRS), a prefeitura municipal de Petrolina instituiu um plano para a construção de uma Usina de Beneficiamento de Entulhos (UBE). Este plano teve por objetivo minimizar o impacto ambiental causado pelo volume de RCD gerado, com possibilidade de reaproveitar os resíduos para fabricação de blocos, bem como contribuir com a geração de emprego e renda para a população carente da região.

A referida usina foi instalada na Central de Tratamento de Resíduos de Petrolina (CTRP), que iniciou suas atividades no final de 2006, em caráter exclusivo de concessão, por um período de 20 anos, com o objetivo de promover a remediação de uma área de 22,0 hectares, localizada no perímetro urbano da cidade e caracterizada, naquela data, como área de lixão.

Em 2008, a instalação da UBE, na CTRP, veio ampliar o gerenciamento de resíduos na cidade, contribuindo para minimizar os impactos ambientais causados pela sua deposição irregular, baseando-se nos exemplos de algumas cidades brasileiras, tais como São Carlos, São Paulo e Belo Horizonte, citadas por Paula (2010). Até esta data, esta UBE é a única responsável pela reciclagem de RCDs na cidade.

Apesar da existência da usina de beneficiamento, devido à ausência de informações relativas ao gerenciamento de RCDs em Petrolina, o objetivo desta pesquisa foi identificar potencialidades e fragilidades no processo de reciclagem de RCDs realizado na UBE e propor ações para melhoria do seu gerenciamento.

\section{FUNDAMENTAÇÃO TEÓRICA}

A gestão ambiental é necessária para atingir as metas de desenvolvimento sustentável (Guimarães et al., 2011). No caso da construção civil, há o interesse de diversos agentes envolvidos na cadeia (consumidores, investidores, associações e governo) em alertar, estimular e pressionar o setor, para que as empresas mudem sua forma de gerir suas obras (Baptista Júnior e Romanel, 2013).

A reciclagem e a reutilização dos RCDs são vistas como alternativas para minimização dos problemas oriundos do seu descarte inadequado, pois podem trazer benefícios, tais como a redução no consumo de recursos naturais não-renováveis, com a substituição por reciclados; redução de áreas necessárias para aterro, pela minimização de volume de resíduos pela reciclagem; redução do consumo de energia durante o processo de produção e a redução da poluição (Oliveira, 2007). 
Para a construção sustentável, é necessário que haja a redução dos resíduos pelo desenvolvimento de tecnologias limpas, utilização de materiais recicláveis e/ou reutilizáveis, além de adequada coleta e disposição de inertes. Se os RCDs forem selecionados, classificados e adequadamente limpos, podem se transformar em agregados secundários para utilização em aterros ou concretos de baixa resistência (Marques Neto \& Schalch, 2010).

Segundo John (2000), o macrocomplexo da construção civil gera resíduos durante produção de materiais e componentes (como as escórias de alto forno e de aciária, resíduos cerâmicos, entre outros), na atividade de canteiro, durante manutenção, modernização, e por fim, na demolição.

Os RCDs são procedentes de serviços de infraestrutura como terraplanagens e redes de serviços públicos (gás, telefonia, água, esgoto, entre outros) e da execução de novas construções, demolições e reformas, tais como tijolos, blocos cerâmicos, concreto em geral, solos, rochas, metais, resinas, colas, tintas, madeiras e compensados, forros, argamassa, gesso, telhas, pavimento asfáltico, vidros, plásticos, tubulações, fiação elétrica, entre outros, comumente chamados de entulhos de obras, caliça ou metralha (Brasil, 2002). A geração desses resíduos está ligada aos procedimentos escolhidos para execução das obras, incluindo o monitoramento e controle das atividades. Sua taxa de geração pode variar de 400 a $700 \mathrm{~kg} / \mathrm{hab}$.ano, em cidades médias e grandes do Brasil, cujo valor pode variar de acordo com fatores, tais como época, tamanho da cidade, desenvolvimento econômico, momento econômico do país, entre outros (Zanta, 2008). Estima-se, ainda, que para cada tonelada de lixo urbano recolhida, são recolhidas duas toneladas de RCDs (Marques Neto \& Schalch, 2010).

Brasileiro \& Matos (2015) realizaram revisão bibliográfica recente, cujas pesquisas retratam a preocupação quanto à geração dos resíduos provenientes da indústria da construção não somente no Brasil, mas em todo o mundo. De acordo com os autores, os estudos realizados indicaram que o primeiro passo para o adequado gerenciamento do RCD está na obtenção do diagnóstico local. Ressaltaram ainda que, com a Política Nacional de Resíduos Sólidos, espera-se que cada estado da federação adote medidas de reciclagem de RCD, desde a implantação de usinas de britagem para a produção de agregados reciclados até a implantação de medidas que garantam a sua utilização.

De acordo com Rocha (2006), uma usina de britagem conta com os seguintes elementos: pácarregadeira, alimentador vibratório, britador (que pode ser de impacto ou de mandíbula), eletroímã para separação das ferragens, peneiras, mecanismos transportadores, e, eventualmente, sistemas para eliminação de contaminantes. $\mathrm{O}$ britador de impacto promove alta redução de material, dando um formato mais arredondado aos grãos do que outros tipos de britadores, considerando os aspectos granulométricos e de forma (Fabro et al., 2011).

Em 2015, com base na constatação do aumento gradativo da geração de RCDs na União Europeia, Dahlbo et al. (2015) estudaram o desempenho da empresa EU Waste Framework Directive, gerenciadora daqueles resíduos, identificando seus impactos econômicos e ambientais, cuja meta de reciclar $70 \%$ não foi alcançada, sendo necessárias mudanças na fonte para adequada separação e recuperação, devido à dependência com relação a composição daqueles resíduos. De acordo com Cassa et al. (2001), a reciclagem secundária, que corresponde àquela realizada fora da fonte de geração, permite beneficiar uma quantidade maior de entulhos, desde que com a prévia e adequada separação na fonte de geração. Na etapa de separação, Piozevan Júnior (2007) destacou que falhas humanas podem influenciar diretamente na qualidade dos produtos do beneficiamento de RCDs.

Na China, também vem sendo verificado grande aumento dos RCDs. Segundo Wu et al. (2016), isto resultou da rápida urbanização (19\% em 1980 para 54\% em 2013). Os autores destacaram a importância da determinação da quantidade, composição e fluxos dos resíduos gerados. Foram obtidas representações visuais do fluxo de RCDs e estimativas da quantidade de resíduos, sendo consideradas informações úteis para o desenvolvimento de instrumentos de política pública para minimizar a geração de RCDs.

No Brasil, os estudos referentes aos RCDs abordaram experiências no Sudeste, Sul e Nordeste do País. Vedroni (2007) desenvolveu dissertação abordando estudo de caso sobre a 
utilização de RCDs em reaterros de valas nos pavimentos de Piracicaba-SP. Também em São Paulo, Silva et al. (2015) analisaram o comportamento do concreto seco produzido com agregados reciclados mistos de $\mathrm{RCD}$, britados na usina de reciclagem localizada em Osasco e obtiveram resistências à compressão comparáveis aquelas dos concretos obtidos a partir de agregados naturais (referência), sendo destacada a viabilidade da reciclagem do ponto de vista da aplicabilidade do produto. Este tipo de estudo é importante para promover maior confiabilidade, uma vez que, de acordo com Brasileiro \& Matos (2015), os maiores empecilhos para reutilização de RCDs, estão na desconfiança dos construtores e clientes quanto ao bom desempenho dos produtos gerados e também na carência de normas que assegurem a sua aceitação no mercado, devido à sua grande heterogeneidade.

Em Belo Horizonte, Moraes \& Pereira (2012) realizaram um estudo exploratório sobre o modelo de gestão de resíduos de construção adotado pela Prefeitura e constataram que a empresa responsável pela limpeza urbana implantou um Programa para a Correção das Deposições e Reciclagem de RCDs, com destaque para criação de três unidades de reciclagem de entulho. Alguns aspectos foram identificados como a necessidade de maior fiscalização nas construtoras, da conscientização da população e da adoção de novas diretrizes que também objetivem a minimização dos resíduos.

Tessaro et al. (2012) realizaram um diagnóstico quanti-qualitativo da produção de RCDs no município de Pelotas - RG, sendo constatada a real necessidade de implantação de um plano de gerenciamento dos RCDs. Apesar das mudanças na legislação ambiental, verificou-se que nenhuma ação visando seu atendimento foi realizada até aquela data.

Na região Nordeste do Brasil, Azevedo et al. (2006) discutiram o impacto provocado pela geração crescente de RCDs, sugeriram medidas para prevenção da sua geração e propuseram modelo simplificado de fluxo dos RCDs em Salvador-BA, cuja aplicação prevê redução de $30 \%$ na geração dos RCDs. Diante da mesma problemática, Santos (2008) realizou diagnóstico da gestão e destinação final daqueles resíduos no município de Parnamirim/RN, constatando que os representantes das cinco empresas que trabalham com coleta e transporte, bem como os representantes das 14 construtoras participantes da pesquisa possuíam conhecimento mediano sobre a legislação ambiental, não seguiam um modelo de gestão eficiente e ainda realizavam destinação dos resíduos para locais inadequados.

Em estudo realizado por Paschoalin Filho \& Graudenz (2012), quanto ao problema da geração e destinação final dos RCDs em três municípios brasileiros: São Paulo/SP, Uberlândia/MG e Recife/PE, foi abordado que as regiões onde ocorreram as maiores quantidades das deposições irregulares foram aquelas com baixos índices de desenvolvimento social, situadas em zonas de periferia. Este último aspecto também foi registrado por Moraes (2006), que ressaltou ainda a ocupação de áreas extensas e rápido esgotamento da capacidade dos aterros.

Para o município foco deste estudo, foi identificado apenas um estudo de caso, segundo o qual foi obtido diagnóstico qualitativo da geração de resíduos em uma obra de construção de apartamentos residenciais com térreo mais três pavimentos, verificando que a destinação dos resíduos era feita de forma não planejada, havia desperdício de água e a madeira era o único resíduo reaproveitado na obra, sendo os demais componentes dos RCDs colocados em caçamba para aguardar coleta por empresa terceirizada (Nunes et al., 2015).

Quanto à legislação ambiental, deve-se observar a Resolução n ${ }^{\circ} 307$ do Conselho Nacional do Meio Ambiente de 5 de julho de 2002 (Conama, 2002), que estabeleceu diretrizes para a gestão dos RCDs, direcionando responsabilidades para os geradores de RCD, tanto do poder público, quanto da iniciativa privada, bem como definiu e classificou o que é chamado popularmente de “entulho". Além desta Resolução, a Lei No 12.305 de 2 de agosto de 2010, instituiu a Política Nacional de Resíduos Sólidos (PNRS) e dispôs sobre seus princípios, objetivos e instrumentos, bem como sobre as diretrizes relativas à gestão integrada e ao gerenciamento de resíduos sólidos, incluídos os perigosos, as responsabilidades dos geradores e do poder público e os instrumentos econômicos aplicáveis. 
De acordo com as regulamentações citadas, as empresas do setor de construção civil estão obrigadas a ter como objetivo principal não gerar resíduos, caso contrário, devem cuidar de sua reutilização, reciclagem e destinação final. Cada município tem a responsabilidade de estabelecer ações para que seja cumprida a legislação, inclusive, disponibilizar uma área própria para o depósito desses materiais.

Quanto à classe a qual pertence cada resíduo, deve-se observar a atividade que lhes deu origem e os seus constituintes. Para o desenvolvimento desta pesquisa, foi utilizada a Resolução ${ }^{\circ}$ 307 do Conselho Nacional do Meio Ambiente (Conama, 2002) e suas alterações (citadas a seguir), que trata especificamente de RCDs. De acordo a referida resolução, esses resíduos são divididos em quatro classes:

- Classe A - são aqueles reutilizáveis ou recicláveis como agregados, tais como:

- de construção, demolição, reformas e reparos de pavimentação e de outras obras de infraestrutura, inclusive solos provenientes de terraplanagem;

- de construção, demolição, reformas e reparos de edificações: componentes cerâmicos (tijolos, blocos, telhas, placas de revestimento etc.), argamassa e concreto;

- do processo de fabricação e/ou demolição de peças pré-moldadas em concreto (blocos, tubos, meio-fio etc.) produzidas nos canteiros de obras.

- Classe B - são os resíduos recicláveis para outras destinações, tais como plásticos, papel/papelão, metais, vidros, madeiras e outros;

- Classe C - são os resíduos para os quais não foram desenvolvidas tecnologias ou aplicações economicamente viáveis que permitam a sua reciclagem/recuperação, tais como os produtos oriundos do gesso;

- Classe D - são resíduos perigosos oriundos do processo de construção, tais como tintas, solventes, óleos e outros ou aqueles contaminados ou prejudiciais à saúde.

A Resolução 348 de 16 de agosto de 2004 (Conama, 2004) e a Resolução 431 de 24 de maio de 2011 (Conama, 2011) modificaram a classificação da Resolução 307, inserindo o amianto como material perigoso (classe D) e mudando a classificação do gesso, de Classe C para a Classe B. De acordo com a NBR 15114 (Abnt, 2004), apesar de o gesso ter sido reclassificado para classe B, ainda é necessário que este seja depositado em recipiente próprio, não permitindo sua mistura com os demais resíduos da classe $\mathrm{B}$, nem de outras classes.

De acordo com Marques et al. (2013), para os resíduos de Classe B, alguns materiais já dispõem de uma ampla cadeia de reciclagem (papelão, vidro, papel), podendo ser encaminhados para venda ou doados para associações de catadores para posterior reutilização.

Apesar dos transtornos causados, os RCDs podem ser vistos como fontes de materiais alternativos de grande potencial e utilidade na engenharia, uma vez que podem ser utilizado em substituição de materiais naturais extraídos de jazidas ou podem ser transformados em matériaprima para componentes de construção, com qualidade semelhante aos materiais tradicionais (Oliveira, 2007). Partiu desta perspectiva, a motivação para pesquisar sobre as fragilidades e potencialidades do processo de reciclagem de RCD realizada pela UBE do município de Petrolina, esperando-se contribuir com a descrição do cenário atual e promoção de melhorias para o gerenciamento dos resíduos.

\section{ASPECTOS METODOLÓGICOS}

Esta pesquisa trata-se de um estudo de caso (Yin, 2015), devido envolver uma investigação empírica de um processo contemporâneo e real, o qual foi realizado em uma empresa singular do ponto de vista do processo de reciclagem de RCDs, uma vez que a UBE é a única licenciada, em Petrolina-PE, para realização do referido processo. A opção pelo estudo de caso permitiu uma

Revista de Gestão Social e Ambiental - RGSA, São Paulo, v. 10, n. 1, p. 93-109, jan./abr. 2016. 
análise detalhada sobre o processo de reciclagem realizado em uma UBE. De acordo com Yin (2015), o método também possibilita ao investigador lidar com uma completa variedade de evidências, tais como documentos, entrevistas e observações.

Quanto aos fins, esta pesquisa é do tipo descritiva e explicativa, levando em conta o processo de reciclagem de RCD realizado na UBE. Segundo Gil (2002), na pesquisa descritiva é realizada uma descrição de determinada população ou fenômenos, já a pesquisa explicativa tem como preocupação central identificar os fatores que determinam ou contribuem para a ocorrência dos fenômenos. O autor afirma ainda que as duas são complementares, pois, para a identificação dos fatores que determinam um fenômeno, é necessário que este esteja suficientemente descrito e detalhado.

Este estudo também é caracterizado como pesquisa aplicada, uma vez que se espera que os resultados sejam aplicados para a melhoria do gerenciamento dos RCDs. De acordo com Ganga (2012), “[...] a pesquisa aplicada busca gerar conhecimentos para a aplicação prática, dirigidos a soluções de problemas específicos. Esta, por sua vez, envolve verdades e interesses locais".

Para o desenvolvimento da pesquisa, foram utilizados dados primários e secundários (Andrade, 1993). As fontes primárias correspondem aos dados coletados durante visitas à Ctrp, realizadas entre os meses de maio a setembro de 2014, a partir de observações participantes (Gil, 2002) e entrevistas semiestruturadas realizadas com os funcionários do setor administrativo da empresa: a assistente comercial, a responsável pelo setor de recursos humanos e o engenheiro civil responsável. Destaca-se que o setor administrativo conta com apenas três funcionários e o referido engenheiro civil também supervisiona as demais unidades da Ctrp no estado de Pernambuco. Os demais funcionários da empresa atuavam no operacional da UBE, nas atividades do aterro controlado e nas operações de limpeza.

Como dados secundários, os quais, de acordo com Marconi e Lakatos (2003, p.170), possibilitam explorar informações não identificadas ou insuficientes, foram utilizados: 1) Ata de vistoria da UBE, elaborada em 2008, com o intuito de verificar o andamento das atividades necessárias à implantação do maquinário (CTRP, 2008); 2) Relatório Anual de Renovação de Licença de Operação da UBE, elaborado em 2013, contendo dados quantitativos e qualitativos relativos ao processo produtivo da usina, e teve por objetivo avaliar o desempenho ambiental da atividade referente à reciclagem de RCD na empresa para manutenção de licença de operação (Ctrp, 2013). Com base no objetivo, para condução da pesquisa, foram abordadas as seguintes questões:

1 - Qual a quantidade média de entulho beneficiada na unidade por mês/ ano? usina)?

2 - Qual o percentual de aproveitamento do entulho recebido (material adequado para

3 - Qual a capacidade do processo de beneficiamento de RCDs?

4 - Como funciona na prática, a parceria desenvolvida com a prefeitura de Petrolina?

5 - Quais as formas de utilização do agregado produzido?

6 - Quais são as principais formas de reaproveitamento dos resíduos Classe B, pela Ctrp?

7 - Nesta unidade, existe alguma forma para o reaproveitamento do gesso?

8 - Há alguma parceria com as empresas de construção civil, para comercialização do agregado reciclado, ou para recolhimento do entulho?

9 - Qual (is) a (s) dificuldade (s) para a gestão de RCDs na cidade de Petrolina?

10 - A população realiza prática do descarte irregular de RCD?

Para extrair o maior número de informações, foi realizada análise estatística descritiva básica, para obter a média e o desvio-padrão dos dados relativos à quantidade de entulho beneficiada por mês/ano, entre os anos de 2012 e 2013 (Tabela 1), bem como realizada análise de regressão para verificar a existência de correlação dos quantitativos de entulho com o período de operação. Os cálculos e gráficos foram obtidos utilizando o programa R. 
Quanto à forma de abordagem do problema, esta pesquisa é do tipo quali-quantitativa (Roesch, 1999, p. 130), uma vez que, por meio do modelo qualitativo, foi descrito o processo de reciclagem, incluindo análise subjetiva que não pode ser traduzida em números, e, para possibilitar uma análise mais profunda, usou-se também o método quantitativo já que, no tratamento de parte dos dados, utilizou-se técnicas estatísticas.

Finalmente, para a fase da análise, o processo de reciclagem de RCDs realizado na UBE foi adotado como categoria de análise operacional, conforme Kerlinger (1980, p. 46), cujas dimensões e itens de análise estão descritos na figura 1.

\begin{tabular}{|c|c|c|}
\hline Categoria de Análise & Dimensões & Itens de análise \\
\hline \multirow{4}{*}{$\begin{array}{l}\text { Processo de } \\
\text { Reciclagem }\end{array}$} & $\begin{array}{l}\text { Matéria-prima } \\
\text { (entulho) }\end{array}$ & $\begin{array}{l}\text { Disponibilidade: Estimativas da geração de RCD em } \\
\text { Petrolina } \\
\text { Composição } \\
\text { Identificação de contaminantes } \\
\text { Transporte para UBE } \\
\text { Critérios para definição de preços } \\
\text { Fragilidades e potencialidades }\end{array}$ \\
\hline & Etapas & $\begin{array}{l}\text { Registros } \\
\text { Classificação do entulho } \\
\text { Fluxos } \\
\text { Impactos ambientais } \\
\text { Fragilidades e potencialidades }\end{array}$ \\
\hline & Capacidade & $\begin{array}{l}\text { Quantidade de entulho recebido } \\
\text { Capacidade estimada do maquinário } \\
\text { Quantidade média mensal processada } \\
\text { Percentual de aproveitamento (adequado para UBE) } \\
\text { Evolução do volume de RCD reciclado na UBE } \\
\text { Fragilidades e potencialidades }\end{array}$ \\
\hline & Produto & $\begin{array}{l}\text { Qualidade } \\
\text { Formas de utilização } \\
\text { Fragilidades e potencialidades }\end{array}$ \\
\hline
\end{tabular}

Figura 1: categoria, dimensões e critérios de análise da pesquisa.

Fonte: Os autores

\section{RESULTADOS, ANÁLISE E DISCUSSÃO}

A consulta da ata de vistoria da UBE (Ctrp, 2008) permitiu obter informações sobre o maquinário foco deste estudo, o qual foi adquirido pela Prefeitura de Petrolina e financiado pelo Ministério de Ciências e Tecnologia, por meio de um programa que visava impulsionar o gerenciamento de resíduos sólidos no município. Em contrapartida, o órgão municipal ficou responsável pela área da implantação da usina e pela montagem do equipamento.

Tendo em vista as dificuldades de implementação e montagem do equipamento, a Prefeitura permitiu que o maquinário ficasse sob a responsabilidade da Ctrp, por meio de um acordo assinado, conhecido como Termo de Permissão de Uso, e, desde então, é responsável pelo funcionamento do equipamento.

De acordo com as observações feitas em visita ao local e com base na Ctrp (2008), a UBE conta com maior parte dos equipamentos citados por Rocha (2006), exceto o sistema para eliminação de contaminante.

Devido à parceria entre a prefeitura e a Ctrp e com base nos dados obtidos e documentos (Ctrp, 2008; Ctrp, 2013), foi possível analisar como funciona a cadeia de beneficiamento de RCDs no município de Petrolina - PE, contribuindo para adequada identificação das potencialidades e fragilidades do gerenciamento de RCDs. 


\subsection{Cadeia de beneficiamento de RCDs}

A obtenção do agregado, realizada na UBE, é caracterizada como reciclagem secundária, conforme Cassa et al. (2001), o qual apresenta vantagens técnicas e econômicas em relação ao processo que acontece dentro da fonte de geração (reciclagem primária).

O processo de reciclagem em estudo é realizado de acordo com as seguintes etapas (figura 2): recepção e análise visual dos resíduos recebidos; disposição em áreas para triagem e retirada de contaminantes dos resíduos; pré-classificação no alimentador vibratório, britagem, retirada de contaminantes magnetizáveis após a britagem e a separação por meio de peneiras vibratórias em pilhas de agregados reciclados peneirados.

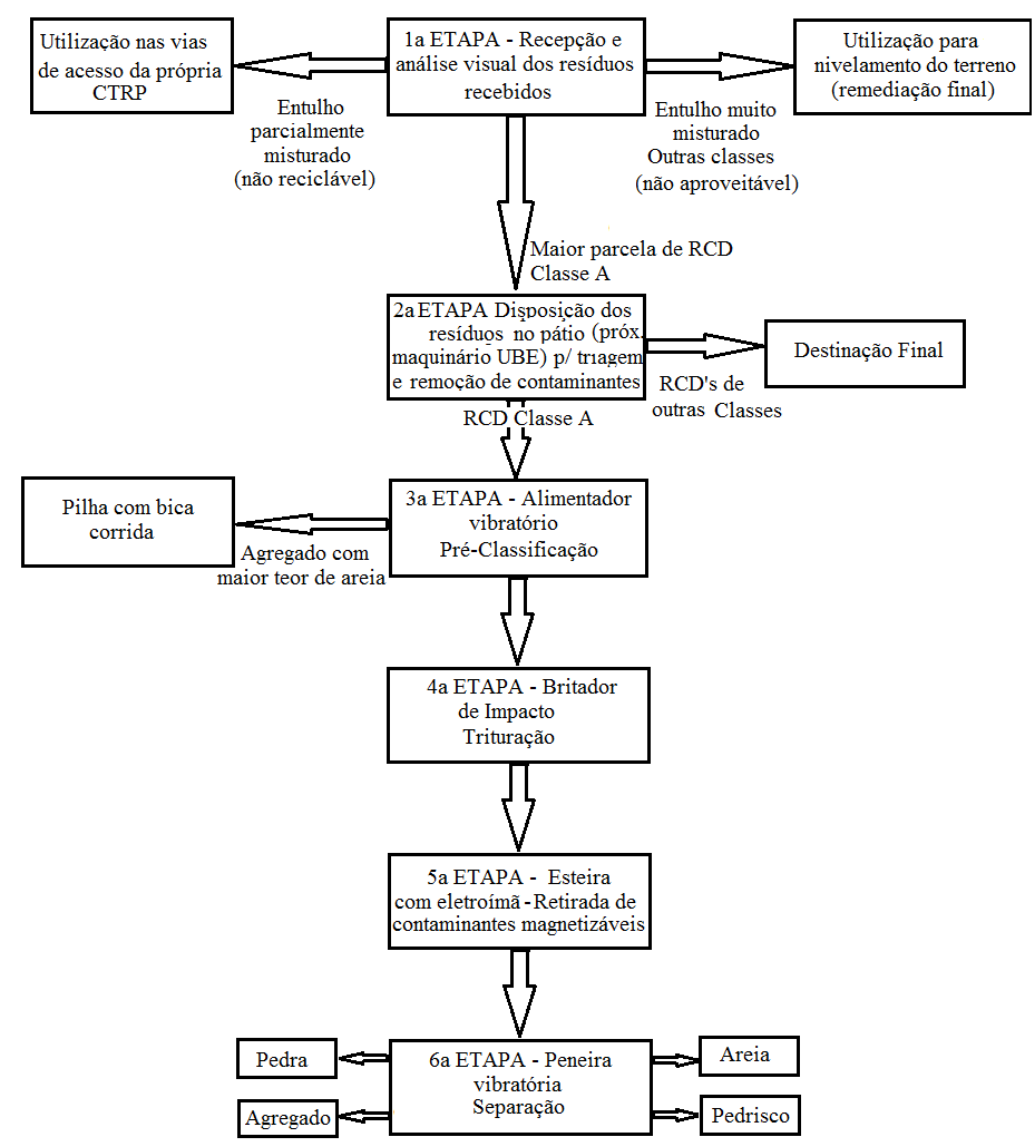

Figura 2: Fluxograma do Processo de Beneficiamento de Entulhos.

Fonte: Os autores

De acordo com o observado durante as visitas, os resíduos provenientes das empresas de construção civil e da limpeza urbana chegam à Ctrp por meio de caminhões, equipados com caçambas estacionárias, que passam por uma balança do tipo rodoviária atrelada a um sistema interligado à Prefeitura Municipal, para que possa ser auditada. A pesagem dos caminhões é realizada com o objetivo de mensurar a quantidade de RCDs, registrando dados como: hora de entrada, saída, origem e transportador. Estes dados permitem que a empresa cobre do gerador o valor relacionado com a massa registrada.

Segundo a assistente comercial da Ctrp, há dificuldade no recebimento de RCD, mesmo cobrando-se um preço abaixo do valor estipulado para outros resíduos. Geralmente, esse preço diminui com a quantidade de resíduos que a empresa deposita na Ctrp, de modo que as propostas de pagamento são analisadas de forma diferenciada para cada gerador. Para RCDs isentos ou com pequena quantidade de impurezas, o custo é menor. Isto é feito visando estimular a segregação do 
resíduo na fonte de geração. O resíduo que adentra a UBE também é recolhido nas proximidades, como parte das atividades diárias da Ctrp, que realiza a limpeza do entorno da área de remediação.

No momento da pesagem, a classificação que é dada ao entulho se refere à predominância dos resíduos que se observa no veículo ou que é declarada pelo motorista. De acordo com os resultados, o percentual de mistura de resíduos de classes distintas é muito alto e apenas uma parcela em torno de $10 \%$ dos RCDs vem sendo considerada adequada para a reciclagem. Neste sentido, na recepção (figura 1 - $1^{\mathrm{a}}$ etapa), a classificação resultante da análise visual permite a segregação do entulho para três destinações diferentes:

1) Se o material for composto de uma parcela muito grande de outros resíduos de Classe II $B$, este material segue para o processo final de remediação do antigo lixão. Neste caso, sendo utilizado para nivelar as áreas dentro da Área de Remediação Ambiental (ARA).

2) Quando o entulho é composto por uma parcela menor de RCD de outras classes, então é utilizado nas vias de acesso da própria Ctrp.

3) A última parcela de material é composta por uma parcela maior de RCD-Classe A, de modo que é estocado no pátio da UBE para a triagem e retirada de contaminantes.

Uma vez classificados, há alternativas distintas para a reutilização ou reciclagem dos RCDs. Para aqueles que pertencem a Classe A, o maior obstáculo para reciclagem está no grau de pureza obtido a partir do processo de segregação. $\mathrm{O}$ uso do entulho bruto tem sido o procedimento menos oneroso, tal como na forma de brita corrida ou em mistura com solo, em bases, sub-bases e revestimentos primários de pavimentação (Baptista Junior et al., 2013; Marques Neto \& Schalch, 2010).

Para reciclagem, faz-se necessário a triagem do resíduo (figura $1-2^{\mathrm{a}}$ etapa), visto que, para iniciar o processo de britagem, peneiramento e estocagem, os resíduos Classe A precisam estar isentos de impurezas. Essa etapa é realizada por funcionários da Ctrp, de forma manual, sendo susceptível à inserção de outros materiais no maquinário, devido falhas humanas. Assim como destacado por Piozevan Júnior (2007), isto poderá influenciar, diretamente, na qualidade do material resultante do beneficiamento de RCDs.

Com bases nas observações feitas e na análise dos documentos (Ctrp, 2008 e Ctrp, 2013), também foi possível constatar que, dentre os principais contaminantes removidos na etapa de triagem dos resíduos na Ctrp, estão: peças de madeira, plásticos, papel/papelão, ferro, algumas peças de gesso e equipamentos de proteção individual.

Apesar de alguns materiais, entre os resíduos de Classe B, já disporem de uma ampla cadeia de reciclagem (Marques et al., 2013), de acordo com as informações obtidas, essa prática não acontece na Ctrp, sendo destacado que estes RCDs são encaminhados para o aterro sanitário. Quanto ao gesso, as peças são reaproveitadas no preenchimento de áreas, fazendo parte do projeto de remediação do aterro controlado.

Uma vez isentos de impurezas, os resíduos Classe A são transportados com o auxílio de uma pá carregadeira, dando início a $3^{\mathrm{a}}$ etapa da reciclagem (figura 2), que ocorre no alimentador vibratório. $\mathrm{O}$ alimentador vibratório tem a função de receber a descarga das pás-carregadeiras e alimentar o britador de impacto. Possui grelhas na extremidade de descarga da mesa vibrante e realizam também a pré-classificação do material, impedindo que partículas mais finas sigam para o britador. Os resíduos com maior teor de partículas finas seguem para um transportador de correia fixa, formando uma pilha de bica corrida ao lado do maquinário. Nesta etapa, o entulho é umedecido a fim de diminuir a emissão de partículas de poeira.

A etapa seguinte é a de trituração, que acontece no britador de impacto (figura 1 - $4^{\text {a }}$ etapa). Assim como destacado por Fabro et al. (2011), este equipamento promove redução do material, dando um formato mais arredondado aos grãos do que outros tipos de britadores. Na Ctrp, o britador conta ainda com sistemas antipó e antirruído, para amenizar impactos ambientais inerentes ao processo.

Seguindo o fluxograma descritivo do processo, os resíduos seguem por uma esteira com eletroímã (figura $1-5^{\mathrm{a}}$ etapa), promovendo retirada dos elementos contaminantes magnetizáveis 
que não foram retirados durante o processo de triagem manual, minimizando falhas humanas. Segundo a assistente comercial da Ctrp, a quantidade deste tipo de contaminante é mínima, sendo estocado numa área e depois encaminhado para reciclagem. No caso de ser considerado rejeito, o metal segue para as células de aterro da própria Ctrp.

Por fim, o material segue por um sistema de correias até a peneira vibratória (figura $2-6^{\mathrm{a}}$ etapa), que os separa em quatro pilhas de agregados reciclados, segundo 4 granulometrias (em metros): areia: $\varnothing<0,0048$; pedrisco: $0,0048<\varnothing<0,0095$; pedra: $0,0095<\varnothing<0,0254$ e agregado: $\varnothing>0,0254$.

Finalmente, quanto às formas de utilização do produto beneficiado na UBE, foram destacados: uso da areia na preparação de argamassas de assentamento de alvenarias de vedação; pedrisco que é utilizado em atividades da própria empresa e também em vias de passeio públicas, ao passo que o agregado reciclado, a depender da sua heterogeneidade, é utilizado na confecção de blocos de concreto, que são disponibilizados para a Prefeitura, que os utiliza em pavimentação de praças e calçadas, ou seja, em aplicações que não requerem um produto com alta resistência. Devido à baixa resistência e produção em pequena escala, não há comercialização dos blocos.

\subsection{Evolução do volume de RCD reciclado na UBE e estimativas da geração de RCD na cidade}

Analisando-se o relatório anual de renovação de licença de operação para o ano 2013 da UBE (Ctrp, 2013), foi constatado que o volume de entulho processado no ano de 2011 foi de 973,75 ton., $39 \%$ a mais que em 2012, cujo total foi de 592,32 ton. (tabela 1). Comparando-se o primeiro trimestre de 2012 com o mesmo período de 2013, é possível observar um decréscimo de mais de $100 \%$ do volume de entulho processados (272,48 ton. em 2012 e 98,46 ton. em 2013) (tabela 1).

Diante do decréscimo, utilizou-se o programa $\mathrm{R}$ para verificar a existência de correlação entre a quantidade de entulho com o tempo, desde janeiro de 2012 a março de 2013, obtendo um coeficiente de correlação igual a 58\%, que, embora baixo, indica decréscimo da quantidade processada no período analisado (figura 3a). Neste sentido, estima-se que se nenhuma ação for tomada, há uma tendência de que a usina saia de operação.

Tabela 1: Quantidade de entulho processada na UBE

\begin{tabular}{cc|cc}
\hline Mês & Quantidade (ton.) & Mês & Quantidade (ton.) \\
\hline jan/12 & 107,73 & $\mathrm{set} / 12$ & 39,89 \\
\hline $\mathrm{fev} / 12$ & 92,00 & $\mathrm{out} / 12$ & 22,68 \\
\hline $\mathrm{mar} / 12$ & 72,65 & $\mathrm{nov} / 12$ & 11,13 \\
\hline $\mathrm{abr} / 12$ & 62,86 & $\mathrm{dez} / 12$ & 22,74 \\
\hline $\mathrm{mai} / 12$ & 79,25 & $\mathrm{jan} / 13$ & 61,68 \\
\hline $\mathrm{jun} / 12$ & 35,63 & $\mathrm{fev} / 13$ & 24,74 \\
\hline $\mathrm{jul} / 12$ & 41,16 & $\mathrm{mar} / 13$ & 12,04 \\
\hline ago/12 & 5,10 & Média & $\mathbf{4 6 , 0 9}$ \\
\hline
\end{tabular}

Fonte: CTRP (2013)

A análise estatística dos dados forneceu uma média de 46,09 ton/mês de material processado, com desvio-padrão de 31,64 ton/mês. Este desvio é bastante alto em comparação à média observada, indicando que não há chegada regular de RCD para processamento. Considerando aquela média e que a UBE pode funcionar ao longo de 26 dias/ mês e 5 horas/dia, uma vez que a empresa optou por ciclos de trabalhos que minimizem o impacto ambiental causado pelos ruídos inerentes ao processo; observa-se que a empresa utilizou apenas 1,8\% de sua capacidade de produção estimada de 2600 ton/mês (informação obtida a partir da pesquisa documental). Dessa forma, o volume de entulhos processados no ano de 2012 e nos primeiros semestres de 2013 está muito aquém da expectativa do Projeto Executivo da Prefeitura Municipal de Petrolina.

Revista de Gestão Social e Ambiental - RGSA, São Paulo, v. 10, n. 1, p. 93-109, jan./abr. 2016. 
A partir do histograma da quantidade de entulho processada por mês (figura $2 b$ ), verifica-se que há maior frequência do processamento entre 10 e 30 toneladas. Apesar da baixa frequência de operação, pode-se observar que a empresa operou a UBE em todos os meses do período analisado.

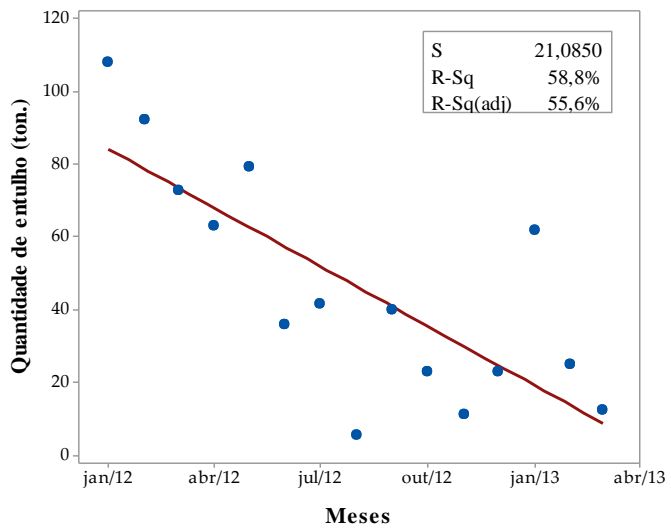

(a)

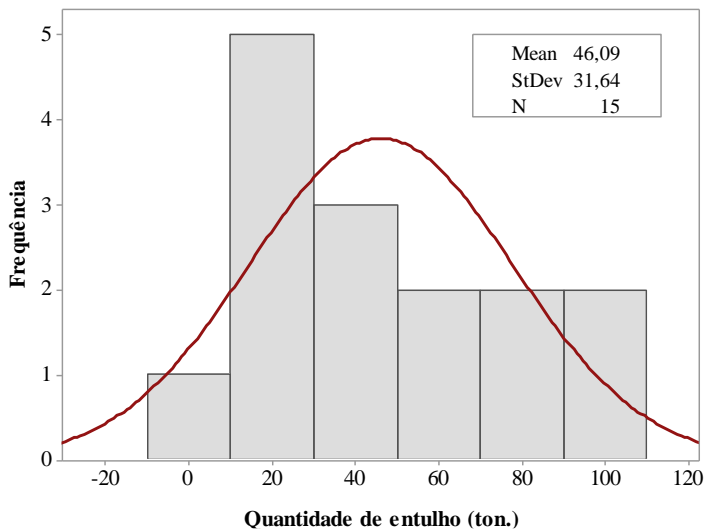

(b)

Figura 3: (a) Análise de regressão linear entre a quantidade de entulhos processada e o tempo (janeiro de 2012 a março de 2013). (b) Histograma da quantidade de entulho processado na UBE no mesmo período.

Fonte: Os autores

De acordo com observações e entrevistas, a empresa aguarda atingir uma dada quantidade de material para então programar a data de operação da UBE. Somente em dois meses do período analisado, houve processamento de 90 a 110 toneladas de entulho (figura 2b). De fato, a quantidade de entulho total processada (691,28 toneladas), nos quinze meses, está abaixo da capacidade mensal de operação da usina (2600 ton./mês).

Os funcionários da UBE associam o decréscimo observado, entre outras causas, a extinção do Programa Tudo Limpo, no qual a Ctrp era responsável pela coleta do RCDs, em pontos específicos da cidade. Para a coleta, eram disponibilizadas caixas estacionárias, colocadas em locais previamente definidos. Os resíduos das construções eram depositados nas caixas e encaminhados à Ctrp para beneficiamento. Entretanto, segundo as informações coletadas, esta atividade estava gerando custos adicionais para a empresa, que afirmou não dispor de frota própria para este fim e que esta atividade não era de responsabilidade da empresa, a qual tem responsabilidade apenas sobre a operação do maquinário.

Até a finalização desta pesquisa, não foram disponibilizados os dados dos meses seguintes do ano de 2013. Como justificativa, foi destacado que os funcionários responsáveis pela UBE estavam redigindo o Relatório Anual de Renovação de Licença de Operação para o ano 2014, fato este que dificultou a disponibilização dos referidos dados.

Apesar da existência da UBE, durante o desenvolvimento desta pesquisa, ainda se verificou a deposição inadequada de RCDs. Estas destinações não foram quantificadas neste estudo. Analisando os dados registrados na tabela 1, percebe-se que a quantidade de RCD-Classe A, processado na UBE, durante quinze meses (691,28 toneladas), foi inferior a quantidade de entulho (714 toneladas) identificada por Santos (2008), os quais foram depositados de forma irregular, entre outubro e novembro de 2007. Embora o entulho englobe materiais não aproveitáveis para reciclagem, tal comparação sugere que a parcela de RCD que adentra a UBE é bastante inferior àquela depositada inadequadamente pela população.

Adicionalmente, de acordo com a estimativa de Zanta (2008), para a taxa de geração de RCD (400 a $700 \mathrm{~kg} / \mathrm{hab}$. Ano), em cidades médias e grandes do Brasil e considerando os dados do Instituto Brasileiro de Geografia e Estatística (Ibge, 2014), quando Petrolina tinha 326.017 
habitantes (cidade média), a geração de RCD estava entre 10.800 a 19.000 ton/mês, constituindo mais um indicativo de elevada demanda pela operação da UBE.

\subsection{Fragilidades e potencialidades da reciclagem de RCD pela UBE}

Dentre as fragilidades observadas, destaca-se a dificuldade no recebimento de RCD "adequado" para a reciclagem, devido à alta heterogeneidade do material, mesmo cobrando-se um preço abaixo do valor estipulado para outros resíduos.

Outra fragilidade associada ao processo de reciclagem de RCDs está na descontinuidade do Programa Tudo Limpo, cuja extinção foi motivada pela falta de um setor responsável, geração de custos adicionais e ausência de valor agregado para o produto reciclado.

Estima-se, que a quantidade de RCD depositado na Ctrp, pelas grandes construtoras do município, é muito aquém do volume gerado nas obras. De acordo com as informações obtidas nas entrevistas, isto pode estar relacionado à carência de material de aterro, o que contribui para que os materiais mais nobres sejam desviados para aterramento e nivelamento de áreas (Ctrp, 2013), a ausência de segregação na fonte geradora e a falta de fiscalização quanto à destinação dos RCDs pelas construtoras.

A baixa resistência dos blocos provenientes do processo de reciclagem de RCD e sua não comercialização não estimula aumento da produção, sendo constatado ainda, que as medidas de resistência não são realizadas periodicamente.

Para avaliar as potencialidades e fragilidades do processo, também foram analisados os aspectos ambientais. Conforme Ctrp (2013), o processo gera uma elevação nos níveis sonoros de ruído no entorno da unidade, principalmente no processamento de materiais mais duros contidos no entulho. Para diminuir este impacto, além de implantação da cortina arbórea, a empresa optou por ciclos de trabalho, preferencialmente, por volta das 10 da manhã, evitando-se os horários entre $12 \mathrm{e}$ 14 horas e também após 17 horas.

Ainda quanto ao ruído, ressalta-se que, com base nos resultados do monitoramento no nível de ruído, os valores variam entre 60 e $65 \mathrm{~dB}$ dentro da empresa, com o equipamento em funcionamento. No lado oposto da rua, estes resultados decaem para valores em torno de $60 \mathrm{~dB}$ e no interior das moradias para menos de $55 \mathrm{~dB}$, sendo um cenário compatível com as recomendações da NBR 10151.

Para mitigar os impactos ambientais inerentes à emissão de poeira, o equipamento é dotado de um sistema de redução de particulado, que dispara jatos de água no momento do despejo do entulho no alimentador vibratório. Porém, este sistema não tem sido suficiente, apenas atenuando a emissão de pó. Como potencialidade, a equipe da Ctrp tomou medidas adicionais, umedecendo as pilhas de entulho bruto, de tal forma que o material estivesse umedecido no momento de ser despejado no alimentador, complementando assim o sistema supracitado. Somente deste modo foi possível diminuir notadamente a emissão de particulado.

Salienta-se que, no projeto de implantação, também foi considerada a direção preferencial dos ventos para minimizar a emissão do particulado para fora da área de remediação, mas direcionando-o, preferencialmente, em direção ao pátio de estocagem na própria UBE. Além disso, no entorno da UBE, foi plantada uma cortina arbórea com eucaliptos, cujo porte contribui para diminuição do impacto visual, bem como a diminuição da emissão de ruído e de poeira. Ademais, os funcionários da UBE salientaram que a Ctrp busca colaborar com pesquisas em diferentes Universidades.

A UBE tem potencial de reciclagem de 2600 toneladas de entulho por mês, a qual vem sendo subutilizada, processando apenas uma média de 46,09 toneladas no mesmo período. Adicionalmente, as estimativas de geração de RCDs na cidade indicam que a busca pela atuação da UBE é de extrema importância para a qualidade de vida dos seus habitantes, cuja capacidade de processamento constitui potencial para adequado gerenciamento dos RCDs. 


\subsection{Proposição de alternativas para minimizar fragilidades}

Para contribuir com a coleta e o recebimento de material, recomenda-se que seja instituído um Plano Integrado de Gerenciamento de Resíduos da Construção Civil (Pigrcc), com aprovação de lei municipal, o qual pode ser discutido dentro da proposta de parceria público-privada entre a Ctrp e a Prefeitura. O referido plano teria como finalidade facilitar a correta disposição, o disciplinamento dos fluxos, a definição dos agentes envolvidos e a consequente destinação adequada dos RCDs, além de fornecer subsídio para o funcionamento da UBE, aproveitando todo o seu potencial de reciclagem. Neste mesmo contexto, pode-se também avaliar a retomada do Programa Tudo Limpo.

Adicionalmente, para uma gestão eficiente dos RCDs, será necessária fiscalização efetiva, minimizando o depósito em áreas irregulares. Esta mesma necessidade foi apontada por Paschoalin Filho \& Graudenz (2012), ressaltando que, apesar de consistir em uma atividade ilegal, ocorre frequentemente o despejo de grandes volumes de RCDs em locais inadequados.

Devido à constatação de que a falta de Gestão de RCDs pelas empresas de construção civil também dificulta as atividades na UBE, por falta de entulho isento de impurezas e pela ausência de implementação de processos mínimos de segregação na fonte, que permitam o aproveitamento de uma parcela maior do material recebido, propõe-se a implementação de programas de gestão de RCDs nas empresas, com adoção de práticas de segregação na fonte.

No que diz respeito à qualidade dos blocos produzidos, propõe-se que sejam realizadas pesquisas em parceria com a Universidade, bem como implementar o monitoramento periódico de suas propriedades e também pesquisas para alterações na formulação dos blocos visando aumentar sua resistência. Estes novos produtos poderiam ser utilizados para outros fins, contribuindo para estimular sua produção em maior escala. Conforme Paula (2010), recomenda-se a implantação de um plano de destinação e agregação de valor para utilização em obras privadas, considerando a comercialização por parte das entidades envolvidas.

\section{CONSIDERAÇÕES FINAIS}

Constatou-se que a UBE vem operando bastante aquém da expectativa inicial e de sua capacidade de processamento, devido, principalmente, à inexistência de material adequado para o processamento na unidade, ao encerramento das atividades do Programa Tudo Limpo e à ausência de gestão de resíduos nas fontes geradoras. No período analisado, houve decréscimo da quantidade processada, estimando-se que, se nenhuma ação for tomada, há uma tendência de que a UBE permaneça subutilizada ou mesmo torne-se inviável sua operação.

As principais fragilidades do processo de reciclagem RCD na UBE estão no recebimento dos resíduos para a operação na UBE: dificuldade na coleta e no transporte do material e sua alta heterogeneidade (aproveitamento em torno de 10\% dos RCDs); nos impactos ambientais causados pelo processo: ruído, poeira; e na qualidade do produto: baixa resistência.

Dentre as potencialidades, destaca-se que a capacidade de processamento da UBE é promissora para a adequada gestão de RCDs na cidade e para redução dos impactos ambientais relacionados com aqueles resíduos. A quantidade de entulho total processada (691,28 toneladas), nos quinze meses da pesquisa, está abaixo da capacidade mensal de operação da usina (2600 toneladas).

Isto posto, propõe-se, para a melhoria do processo de reciclagem na UBE e, consequentemente, da gestão de RCD na cidade, que sejam realizadas ações voltadas para instituição do Pigrcc, com força de lei municipal; programas para segregação do entulho na fonte de

Revista de Gestão Social e Ambiental - RGSA, São Paulo, v. 10, n. 1, p. 93-109, jan./abr. 2016. 
geração; programas para coleta de RCD e parceria com a Universidade para pesquisas visando melhoria da qualidade do produto (blocos) e outras inovações tecnológicas.

Salienta-se que, em resposta ao encaminhamento do estudo realizado, o diretor da Ctrp enviou correspondência eletrônica, destacando que o trabalho desenvolvido irá nortear a empresa na adoção de algumas medidas que irão contribuir para otimização do processo de beneficiamento de resíduos de construção e demolição na unidade e que gostariam de ampliar parceria para desenvolvimento de projetos futuros.

Finalmente, foram corroborados aspectos destacados em pesquisas prévias, com ênfase na preocupação quanto à geração de RCDs; no aumento gradativo da sua geração; na necessidade de maior fiscalização nas empresas e na prática do depósito inadequado dos referidos resíduos pela população. Como avanço, diante da carência de estudos relacionados à temática na região e com base no estudo da cadeia de beneficiamento, foram obtidas a evolução do volume de RCD reciclado; as fragilidades e potencialidades do processo e propostas medidas potencializadoras de mudanças significativas no cenário atual.

Como perspectiva para trabalhos futuros, espera-se ampliar a pesquisa para inserção da análise da percepção dos demais agentes da cadeia do sistema de beneficiamento, tais como os clientes da UBE (construtores e pessoas físicas) e representante da prefeitura.

\section{REFERÊNCIAS}

Associação Brasileira de Normas Técnicas (Abnt) NBR 15114 (2004) Resíduos sólidos da construção civil - Áreas de reciclagem - Diretrizes para projeto, implantação e operação. Rio de Janeiro.

Azevedo, G. O. D. de, Kiperstok, A \& Moraes, L. R. S. (2006) Resíduos da construção civil em Salvador: os caminhos para uma gestão sustentável. Engenharia Sanitária Ambiental,11 (1), 65-75.

Baptista Júnior, J. V. \& Romanel, C. (2013) Sustentabilidade na indústria da construção: uma logística para reciclagem dos resíduos de pequenas obras. URBE, Revista Brasileira de Gestão Urbana. vol. 5 (2), 27-37.

Brasileiro, L. L. \& Matos, J. M. E. (2015) Revisão bibliográfica: reutilização de resíduos da construção e demolição na indústria da construção civil. Cerâmica. 61 (358), 178-189.

Cassa, J. C., Carneiro, A. P. \& Brum, I. A. S. (2001) Reciclagem de entulho para produção de materiais de construção: projeto entulho bom. Salvador: Edufba. Caixa Econômica Federal.

Conselho Nacional de Meio Ambiente-Conama (2002) Resolução n. 307, 05 de julho de 2002. Estabelece diretrizes, critérios e procedimentos para a gestão dos resíduos da construção civil. Diário Oficial da União, Brasília, DF. Recuperado em: 20 de maio de 2015, de:

<http://www.mma.gov.br/port/conama/-index.cfm>.

Conselho Nacional de Meio Ambiente-Conama (2004) Resolução n. 348, 16 de agosto de 2004. Altera a Resolução Conama n. 307, de 5 de julho de 2002, incluindo o amianto na classe de resíduos perigosos. Diário Oficial da União, Brasília, DF, Recuperado em: 19 de maio de 2015, de: <http://www.mma.gov.br/port/conama/-index.cfm>.

Conselho Nacional de Meio Ambiente-Conama (2011) Resolução 431 de 24 de maio de 2011. Altera o art. $3 o$ da Resolução n. 307, de 5 de julho de 2002. Diário Oficial da União, Brasília, DF, Recuperado em: 21 de maio de 2015, de: <http://www.mma.gov.br/port/conama/-index.cfm>. 
Ctrp (2008) [Ata de vistoria da usina de beneficiamento de entulhos]. Petrolina: CTRP.

Ctrp (2013) [Relatório anual de renovação de licença de operação da usina de beneficiamento de entulhos]. Petrolina: Ctrp.

Dahlbo, H., Bachér, J., Lähtinen K., Jouttijärvi, T., Suoheimo, P., Mattila, T., Sironen, S., Myllymaa, T., Saramäki, K. (2015) Construction and demolition waste management - a holistic evaluation of environmental performance. Journal of Cleaner Production. 107, 333-341.

Fabro, F., Gava, G. P., Grigoli, H. B. \& Meneghetti, L. C. (2011) Influence of fine aggregates particle shape in the concrete properties. Revista Ibracon de estruturas e materiais. 4 (2), 191-212.

Farias, A. B. de, Bahia, N. C., Sukar, S. F. \& Gusmão, A. D. (2011) Diagnóstico da gestão de resíduos da construção civil no município de Olinda/PE. In: Encontro Nacional, 6 e Encontro Latino-americano sobre Edificações e Comunidades Sustentáveis, 4. 7-9 set.

Ganga, G. M. D. (2012) Trabalho de conclusão de curso (TCC) na engenharia de produção: um guia prático de conteúdo e forma. São Paulo: Atlas.

Gil, A.C. (2002) Como elaborar projetos de pesquisa. (4. ed.) São Paulo: Atlas.

Guimarães T., Trimer, R., Cairo, S., Françozo, M., Babaoka, T., Coachman, E. \& Garcia, L. (2011) Gestão ambiental. (4 ed.) São Paulo: Editora Pearson.

Instituto Brasileiro de Geografia e Estatística-Ibge (2014) Censo 2014. Rio de Janeiro: IBGE. Recuperado em 12 agosto, 2015, de

ftp://ftp.ibge.gov.br/Estimativas_de_Populacao/Estimativas_2014/estimativa_dou_2014.pdf.

John, V. M.(2000) Reciclagem de resíduos na construção civil: contribuição para metodologia de pesquisa e desenvolvimento. Tese (Livre Docência) - Escola Politécnica - Universidade de São Paulo. São Paulo.

Kerlinger, F. (1980) Metodologia da Pesquisa em Ciências Sociais. São Paulo: E.P.U/Edusp.

Lei $\mathrm{n}^{\circ}$ 12.305, de 2 de agosto de 2010 (2010). Institui a Política Nacional de Resíduos Sólidos; altera a Lei $n^{\circ}$ 9.605, de 12 de fevereiro de 1988; e dá outras providências. Diário Oficial da União, Brasília, DF.

Marconi, M. de A. \& Lakatos, E. M. (2003) Fundamentos de metodologia científica. (5. ed.) São Paulo: Atlas.

Marques, O. B., Oliveira, M. R. S. \& Picanço, A. P. (2013) Resíduos da construção civil: geração e alternativas para reciclagem em um canteiro de obras de pequeno porte. Revista de Engenharia Ambiental. Espírito Santo do Pinhal, 10 (2), 143-156.

Marques Neto, J. da C \& Schalch, V. (2010) Gestão dos resíduos de construção e demolição: Estudo da situação no município de São Carlos-SP, Revista Engenharia Civil. Brasil. (36), 41-50.

Moraes, G. M. D. (2006) Diagnóstico da deposição clandestina de resíduos da construção e demolição em bairros periféricos de Uberlândia: subsídio para uma gestão sustentável. Dissertação 
de Mestrado, Departamento de Engenharia Civil, Universidade Federal de Uberlândia, Uberlândia, MG, Brasil.

Moraes, R. de O. \& Pereira, P. M. S. (2012) O Programa de manejo diferenciado e reciclagem de resíduos da Prefeitura de Belo Horizonte. Revista de Gestão Social e Ambiental, 6 (1), 117-126.

Nunes, S. M., Santos, V. M. L. dos \& Santos Júnior, J. E. dos. (2015) Avaliação dos resíduos de construção em um canteiro de obra em Petrolina- PE. Revista Eletrônica em Gestão, Educação e Tecnologia Ambiental, 19 (2), 382-391.

Oliveira, J. C. de. (2007) Indicadores de potencialidades e desempenho de agregados reciclados de resíduos sólidos da construção civil em pavimentos flexíveis. Tese de Doutorado - Departamento de Ciências - Universidade de Brasília, Brasília.

Paschoalin Filho, J. A. \& Graudenz, G. S. (2012) Destinação irregular de resíduos de construção e demolição (RCD) e seus impactos na saúde coletiva. Revista de Gestão Social e Ambiental. 6 (1), 127-142.

Paula, P. R. F. de. (2010) Utilização dos resíduos da construção civil na produção de argamassa sem função estrutural. Dissertação de Mestrado. Departamento de Engenharia Civil - Universidade Católica de Pernambuco, Recife.

Piozevan Júnior, G. T. A. (2007) Avaliação dos resíduos da construção civil (RCC) gerados no município de Santa Maria. Dissertação de Mestrado, Departamento de Engenharia Civil, Universidade Federal de Santa Maria, Santa Maria, RS, Brasil.

Prado Filho, J. F. DO \& Sobreira, F. G. (2007) Desempenho operacional e ambiental de unidades de reciclagem e disposição final de resíduos sólidos domésticos financiadas pelo ICMS Ecológico de Minas Gerais. Engenharia Sanitária Ambiental. 12 (1), 52-61.

Rocha, E. G. de A. (2006) Os resíduos sólidos de construção e demolição gerenciamento, quantificação e caracterização: Um estudo de caso no Distrito Federal. Dissertação de Mestrado Departamento de Engenharia Civil - Universidade de Brasília. Brasília.

Roesch, S. M. A. (1999) Projetos de estágio e de pesquisa em Administração. (2. ed.) São Paulo: Atlas.

Santos, A. N. (2008) Diagnóstico da situação dos resíduos de construção e demolição (rcd) no município de Petrolina (PE). Dissertação de Mestrado, Departamento de Engenharia - Universidade Católica de Pernambuco, Recife.

Silva, R. B. da, Ângulo, S. C., Pileggi, R. G. \& Silva, C. O. (2015) Concretos secos produzidos com agregados reciclados de RCD separados por densidade. Ambiente Construído. 15, (4), 335-349.

Tessaro, A. B., Sá, J. S. de \& Scremin, L. B. (2012) Quantificação e classificação dos resíduos procedentes da construção civil e demolição no município de Pelotas, RS. Ambiente Construído. 12, (2), 121-130.

Vedroni, J. W. (2007) Estudo de caso sobre a utilização do RCD (resíduos de construção e demolição) em reaterros de valas nos pavimentos de Piracicaba SP. Dissertação de Mestrado, Faculdade de Engenharia Agrícola - Universidade Estadual de Campinas, Brasil. 
Wu, H., Wang, J., Duan, H., Ouyang L., Huang W. \& Zuo J. (2016) An innovative approach to managing demolition waste via GIS (geographic information system): a case study in Shenzhen city, China. Journal of Cleaner Production. 112, 494-503.

Yin, R. K. (2015) Estudo de caso: planejamento e métodos. (5.ed.) Porto Alegre: Bookman.

Zanta, V. M. (2008) Coordenação Geral Núcleo Regional do Nordeste- (Nurene). Resíduos sólidos: gerenciamento e reciclagem de resíduo de construção e demolição - RCDs. [Guia Do Profissional em Treinamento Níveis 1 E 2]. Salvador: ReCESA.

Data da submissão: 25/11/2015

Data da publicação: 30/04/2016 